\title{
Seizure and Profound Hypokalaemia: Unusual Presentation of Primary Hyperparathyroidism
}

\author{
Yasuto Nakasone ${ }^{1}$, Shinya Uchino ${ }^{2}$, Yuka Sato ${ }^{1}$, Keishi Yamauchi ${ }^{1}$, Toru Aizawa $^{1}$ \\ ${ }^{1}$ Diabetes Center, Aizawa Hospital, Matsumoto, Japan, \\ ${ }^{2}$ Noguchi Thyroid Clinic and Hospital Foundation, Beppu, Japan
}

Received: 03/03/2015

Accepted: $12 / 05 / 2015$

Published: 29/06/2015

How to cite this article: Nakasone Y, Uchino S, Sato Y, Aizawa T. Seizure and profound Hypokalaemia: unusual presentation of primary hyperparathyroidism. EJCRIM 2015;2:doi: 10.12890/2015_000196

Conflicts of Interests: The authors declare that they have no conflicts of interest in this research.

This article is licensed under a Commons Attribution Non-Commercial 4.0 License

\begin{abstract}
A 68-year-old man was admitted because of tonic-clonic convulsion. He had been receiving 200 mg itraconazole for 10 days. He had hypokalaemia $(2.2 \mathrm{mEq} / \mathrm{l})$, hypercalcaemia $\left(\mathrm{Ca}_{\text {corr }} 11.0 \mathrm{mg} / \mathrm{dl}\right)$ and elevated serum parathyroid hormone (PTH, $\left.95 \mathrm{pg} / \mathrm{ml}\right) . \mathrm{Ultrasound}$ examination of the neck revealed a low echoic tumour. Cessation of itraconazole and fluid supplementation eradicated clinical symptoms and profound hypokalaemia, but serum potassium remained low normal $(3.4 \mathrm{mEq} / \mathrm{l})$ and the mild hypercalcaemia and elevated PTH were unchanged. To conclude, a small amount of itraconazole $(200 \mathrm{mg})$ precipitated profound hypokalaemia and seizure in a patient with mild hyperparathyroidism and low normal serum potassium.
\end{abstract}

\section{LEARNING POINTS}

- The clinical presentation of hyperparathyroidism is very diverse.

- Determination of corrected calcium is mandatory in critical care units.

- A few minor things occurring together can have major clinical consequences.

\section{KEYWORDS}

Seizure, hypokalaemia, hyperparathyroidism, itraconazole.

\section{INTRODUCTION}

A diagnosis of mild primary hyperparathyroidism (PHPT) in an asymptomatic patient is not uncommon. Indeed, we encountered a patient with very mild PHPT whose main problems were seizure and profound hypokalaemia.

\section{CASE REPORT}

A 68-year-old man was transferred to our emergency department due to tonic-clonic convulsion of the left upper extremity.

He had mild diarrhoea for 2 days prior to this event. He had been operated on for a pyogenic iliopsoas abscess and had been receiving 200 mg minocycline, $750 \mathrm{mg}$ metronidazole and $200 \mathrm{mg}$ itraconazole postoperatively for 10 days. Family history was not contributory. His serum potassium had been slightly depressed ( $3.1 \mathrm{mEq} / \mathrm{l})$ before operation for the iliopsoas abscess (i.e. prior to the administration of itraconazole). Upon arrival, the patient no longer had seizures. There was no focal neurological deficit. He appeared poorly nourished (body mass index $20.0 \mathrm{~kg} / \mathrm{m}^{2}$ ) with signs of mild dehydration such as a dry tongue and reduced skin turgor. Vital signs were body temperature $36.6^{\circ} \mathrm{C}$, blood pressure $145 / 77 \mathrm{mmHg}$, pulse rate $56 / \mathrm{min}$ and respiration rate $22 / \mathrm{min}$. A small (ca. $1.0 \mathrm{~cm}$ in diameter) elastic firm non-tender nodule was palpable on the right side of the anterior neck. Laboratory data are shown in Table 1.

There was profound hypokalaemia ( $2.2 \mathrm{mEq} / \mathrm{l}$ ), mild hypercalcaemia (calcium corrected for albumin $11.0 \mathrm{mg} / \mathrm{dl}$ ), mild normocytic anaemia, high arterial $\mathrm{pH}$ (7.509) and elevated base excess (7.6 mmol/l). He was admitted for further evaluation. 


\begin{tabular}{|c|c|c|c|}
\hline A. Chemistry & & B. Blood count & \\
\hline Total protein g/dl (6.7-8.3) & 5.5 & Leukocytes / $/ \mu \mathrm{l}(4,000-8,500)$ & 3,000 \\
\hline Albumin g/dl (3.8-5.1) & 2.4 & Red cells $\times 10^{4} / \mu \mathrm{l}(410-530)$ & 322 \\
\hline Serum creatinine $\mathrm{mg} / \mathrm{dl}(0.4-0.7)$ & 0.97 & Haematocrit \% (39.0-52.0) & 31.7 \\
\hline $\begin{array}{l}\text { Total calcium corrected for albu- } \\
\mathrm{min} \mathrm{mg} / \mathrm{dl}(8.5-10.5)\end{array}$ & 11.0 & Platelets $\times 10^{4} / \mu \mathrm{l}(14.0-44.0)$ & 16.4 \\
\hline $\begin{array}{l}\text { lonized calcium mmol/l (1.21- } \\
\text { 1.36) }\end{array}$ & 1.44 & C. Arterial blood gas & \\
\hline Phosphate mg/dl (2.5-4.5) & 2.9 & $\mathrm{pH}(7.35-7.45)$ & 7.509 \\
\hline Potassium mEq/l (3.4-4.8) & 2.2 & Base excess mmol/l (-2 to 2$)$ & 7.6 \\
\hline Sodium mEq/l (135-147) & 147 & $\mathrm{HCO}_{3}^{--} \mathrm{mmol} / \mathrm{l}(20-26)$ & 31.3 \\
\hline Chloride mEq/l (98-110) & 107 & $\mathrm{pO}_{2} \mathrm{mmHg}(80-100)$ & 78.7 \\
\hline Magnesium mg/dl (1.8-2.6) & 2.1 & $\mathrm{pCO}_{2} \mathrm{mmHg}(35-45)$ & 40.2 \\
\hline $\mathrm{FE}_{\mathrm{Ca}_{2}}(0.02-0.04)$ & 0.025 & Anion gap $\mathrm{mEq} / \mathrm{l}(10-12)$ & 8.7 \\
\hline Intact PTH pg/ml & 95 & D. BMD & \\
\hline $1,25(\mathrm{OH})_{2} \mathrm{D}_{3} \mathrm{pmol} / \mathrm{l}(20-70)$ & 15.7 & Femur (>-2.5) & -2.7 \\
\hline $25(\mathrm{OH}) \mathrm{D} \mathrm{ng} / \mathrm{ml}(7-41)$ & 9. & $\mathrm{~L} 2-4(>-2.5)$ & -2.9 \\
\hline Bone ALP $\mu g / I(3.8-22.6)$ & 16.1 & E. Urinary electrolytes & \\
\hline Corticotropin pg/ml (7.2-63.3) & 35.6 & Calcium mg/l & 220 \\
\hline Cortisol pg/dl (4.0-18.3) & 15.1 & Phosphate mg/l & 532 \\
\hline Aldosterone pg/ml (35.7-240) & 29.2 & Potassium mEq/l & 19.3 \\
\hline PRA ng/ml/h (0.3-5.4) & 0.2 & & \\
\hline PTHrp pmol/l ( $<1.1)$ & U.D. & & \\
\hline NTx nmol BCE/I (10.7-24.0) & 49.8 & & \\
\hline
\end{tabular}

Table 1: Laboratory data.

$B C E$, bone collagen equivalent; $B M D$, bone mineral density; $F E_{C \text {, }}$ fractional excretion of calcium; $N T x, N$-terminal teropeptide; PRA, plasma renin activity; PTH, parathyroid hormone; PTHrp, PTH-related peptide; U.D., undetectable. Intact PTH was measured using a Roche Elecsys ${ }^{\circledR}$ chemiluminescence immunoassay at SRL, Tokyo. The reference range is indicated in the parentheses.

Serum ionized calcium and serum intact parathyroid hormone (PTH) were elevated, Fractional excretion of calcium (FE $\mathrm{Ca}_{\mathrm{a}}$ ) was normal and \% tubular reabsorption of phosphate (TRP) was lowered. Regarding indices of bone turnover, serum bone alkaline phosphatase was normal, but urinary N-terminal telopeptide (NTX) was elevated. Bone mineral density (BMD) was below age- and gender-based norms. The serum level of $1,25(\mathrm{OH})_{2} \mathrm{D}_{3}$ was suppressed despite a normal level of $25(\mathrm{OH}) \mathrm{D}$, and $\mathrm{PTH}$-related peptide was undetectable. Ultrasound examination of the neck revealed a low echoic tumour $(2.3 \times 4.7 \times 2.2 \mathrm{~mm})$ behind the left lobe of the thyroid gland and a cyst with inhomogeneous internal echogenicity $(9.9 \times 6.9 \times 14.7 \mathrm{~mm})$ behind the right lobe of the thyroid, suggesting parathyroid or thyroid cystic adenomas. CT scans of the brain and chest found no abnormalities. An abdominal CT scan revealed a stone in the right ureter and hydronephrosis, but no tumour in the pancreas or adrenal glands. Plasma renin activity and serum aldosterone concentration were slightly suppressed and urinary potassium excretion was not increased. No germ-line mutation could be found in the calcium sensing receptor (CaSR) gene.

Supplementation of fluid (1,000 ml on day 1 ) and potassium ( $94 \mathrm{mEq}$ on day 1; $64 \mathrm{mEq}$ on days 2 and 3; and $32 \mathrm{mEq}$ on days 4-6) was performed and itraconazole discontinued. The treatment eradicated the overt hypokalaemia and normalized the arterial pH. Seizure and diarrhoea did not recur after these procedures. Nevertheless, serum calcium remained mildly elevated and the serum intact PTH concentration transiently returned to normal $(62 \mathrm{pg} / \mathrm{ml})$ on day 8 . For the past 10 months, the patient has been completely asymptomatic. Low normal serum potassium (3.4-3.9 mEq/l) and mild hypercalcaemia (11.5-11.6 mg/dl after correction for albumin) with a modest elevation in intact PTH (91-101 pg/ml) were present at follow-up at 6-10 months.

Because the patient did not accept our proposal of further evaluation such as scintigraphy in preparation for possible parathyroidectomy, careful observational follow-up is being continued.

\section{DISCUSSION}

The clinical presentation of mild PHPT in this patient was extremely unusual. The initial symptom was transient seizure, which was most likely due to profound hypokalaemia. Although itraconazole had been administered, the duration of treatment was only 10 days and dosing was only $200 \mathrm{mg}$, so it was most unlikely that administration of itraconazole alone caused such profound hypokalaemia ${ }^{[1]}$. Of note, the patient was modestly hypokalaemic even before administration of itraconazole and after its cessation, suggesting that the PHPT may have been related to the hypokalaemia. In fact, Aldinger and Samaan reported that $16.9 \%$ of patients with hyperparathyroidism had hypokalaemia ${ }^{[2]}$. However, hyperparathyroidism per se was not associated with profound hypokalaemia as low as $2.2 \mathrm{mEq} / \mathrm{I}^{[2]}$. 


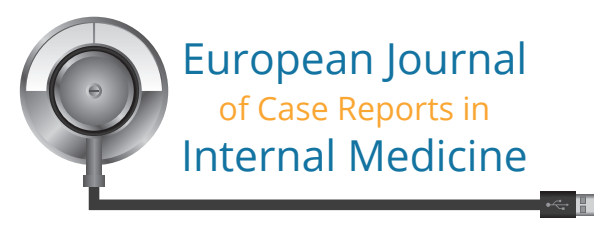

Although the mechanism of hypokalaemia in PHPT is not well understood, metabolic alkalosis might be a candidate. Excess PTH has been shown to cause alkalosis and chronic hypercalcaemia can induce so-called contraction alkalosis.

Seizure due to hypercalcaemia occurs only if hypercalcaemia is very severe due to highly active PHPT ${ }^{[3]}$. However, PHPT was very mild in this patient, so it cannot have been the sole cause of seizure. Due to the mildness of the PHPT, not all laboratory data were typical for PHPT. Namely, lowered \% TRP, reduced BMD and the presence of a urinary stone and normocytic anaemia were compatible with the diagnosis of PHPT. On the other hand, decreased $1.25(\mathrm{OH})_{2} \mathrm{D}_{3}$ despite normal 25(OH)D indicating non-enhanced 25-hydroxyvitamin $\mathrm{D}_{3}$ 1-alpha-hydroxylase, and normal bone alkaline phosphatase pointing to absence of increased bone turnover, were not indicative of PHPT. Moreover, the serum concentration of intact PTH fluctuated spontaneously above and below the upper limit of the reference range in this patient, which was also observed in $13 \%$ (108/861) of patients with sporadic $\mathrm{PHPT}^{[4]}$ in a previous study. Although a rare adult case of mild hypercalcaemia with a mutation in CaSR has been reported ${ }^{[5]}$, there was no inactivating mutation of CaSR in this patient. Multiple endocrine neoplasia and malignancy-associated hypercalcaemia were ruled out with appropriate tests.

\section{CONCLUSIONS}

Our patient with mild PHPT experienced profound hypokalaemia and seizure after administration of 200 mg itraconazole for 10 days. He was modestly hypokalaemic both before itraconazole administration and after its cessation. We believe the small dose of itraconazole and PHPT acted synergistically to produce profound hypokalaemia. Diarrhoea, albeit mild, might have worsened the hypokalaemia as well. So, an accumulation of mild triggering factors for hypokalaemia precipitated hypokalaemia severe enough to cause a seizure.

\section{REFERENCES}

1. Amichai B, Grunwald MH. Adverse drug reactions of the new oral antifungal agents--terbinafine, fluconazole, and itraconazole. Int J Dermatol 1998;37:410-415.

2. Aldinger KA, Samaan NA. Hypokalemia with hypercalcemia: Prevalence and significance in treatment. Ann Intern Med 1977:87:571-573.

. Bayat-Mokhtari F, Palmieri GM, Moinuddin M, Pourmand R. Parathyroid storm. Arch Intern Med 1980;140:1092-1095.

4. Amin AL, Wang TS, Wade TJ, Yen TW. Normal PTH levels in primary hyperparathyroidism: still the same disease? Ann Surg Oncol 2011;18:3437-3442.

5. Kim DD, Que L, Raizis AM, Florkowski CM. Novel inactivating mutation of the calcium-sensing receptor in a young woman with mild hypercalcaemia. Intern Med J 2014;44:413-416. 